\title{
Tegching
Methods
}

\section{A Laboratory Exercise to Demonstrate Embryo Rescue}

\author{
Ron G. Goldy and \\ Dana F. Moxley
}

Additional index words. embryo culture, plant tissue culture

Summary. A laboratory exercise is outlined and discussed for embryo culture of bean, corn, and pea embryos. Fresh, inexpensive material is generally available for these crop species throughout the year. The exercise gives students experience in embryo excision and exposure to some benefits of embryo rescue. Embryos from the three species are identified easily and can be removed without magnification, and data can be obtained within 3 weeks after culture. Further investigations using embryos are suggested.

$\mathbf{E}$ mbryo rescue has become an important tool for plant breeders (Ramming, 1983), helping them obtain sexual hybrids from: difficult-to-cross species (Goldy et al., 1988), early maturing fruit (Smith et al., 1969), and "seedless" grapes (Emershad et al., 1989). It no longer is just a research tool, but is used on a large scale by stone fruit and grape breeders to obtain earlier-maturing and seedless genotypes, respectively.

Due to increasing importance, embryo rescue has become a common exercise in many teaching laboratories. Many of these exercises use fully mature, dry seed that is imbibed before embryo excision (Reinert and Yeoman, 1982) and are more centered on embryo excision than benefits of embryo rescue, since mature seeds germinate well without excision. The laboratory exercise outlined here uses nearly mature, fresh seed from three crop species-bean ( Phaseolus vulgaris L.), corn (Zea mays L.), and pea ( Pisum sativim L.). Students are exposed to embryo excision techniques, and also to the benefits of embryo rescue, since immature seeds germinate poorly without rescue in nutrient media.

Fresh beans, corn, and peas were purchased from a local grocery store, seeds were removed from the fruit (Fig. 1A), surface-sterilized in $20 \%$ sodium hypochlorite for $20 \mathrm{~min}$, and rinsed three times in sterile, distilled water. Two drops of a mild detergent were added to each $250 \mathrm{ml}$ of disinfecting solution. Embryos were excised (Fig. 1B) using aseptic techniques and placed on Murashige and Skoog (MS) media containing $20 \mathrm{~g}$ of sucrose/liter (MS media can be purchased in a powdered form from commercial suppliers) in standard petri dishes containing $25 \mathrm{ml}$ of media. Three embryos from each species were placed in each dish so that each contained nine embryos. For controls, excised embryos or ovules (seed) were placed in petri dishes on moist filter paper, and seeds also were placed in sterilized soil. Petri dishes were sealed with parafilm and placed in ambient temperature and light in a north-facing window, or in a growth room. Seeds in soil were placed only in ambi- ent conditions in a north-facing window. Embryos and seeds were observed for germination and subsequent growth. Culture began in early June and was repeated five times through mid-August;

Corn embryos responded better than bean or pea to any of the rescue attempts (Fig. 1C). Radicle extension on corn could be observed within 24 $\mathrm{h}$, and within 3 weeks the roots began to curve around the petri dish. Bean and pea embryos were similar in germination and growth capabilities. No visible differences were observed between embryos grown in a growth room and those grown in ambient conditions. Also, time of year did not appear to affect germination and growth.

Half-strength MS media also was used, with the only observed difference being a slower growth rate. Peas are reported to grow better on B5 media (Gantotti and Kartha, 1986); therefore, B5 (Gamborg et al., 1968) media containing 5 or $10 \mathrm{~g}$ sucrose/ liter was tried, but it proved to be inferior to MS media. Stunted growth and large amounts of callus were observed at both sucrose levels when embryos were placed on B5 media.

By comparison, growth of embryos placed on moist filter paper was slow and eventually ceased due to lack ofnutrients. On moist filter paper only pea seeds were observed to germinate-others eventually deteriorated. Poor germination was observed in all three species from seed placed in soil, with most deteriorating.

A common problem experienced in tissue culture laboratories is contamination. The three species used here have ovules that easily separate from the fruit and smooth seedcoats, which facilitate effective disinfection. Corn ovules are removed easily if the ear is broken in half and the ovules are removed from the broken end using a scalpel. Having the tissue of interest well-protected by the seedcoat also allows for the severe disinfecting treatment. Uniqueness of each seed makes it possible to place them in the same container for disinfecting and then separating them as the embryos are excised. No contamination was observed in any of the cultures.

The three species have large seed and embryo size, allowing easy handling and embryo identification without magnification. They are also avail- 

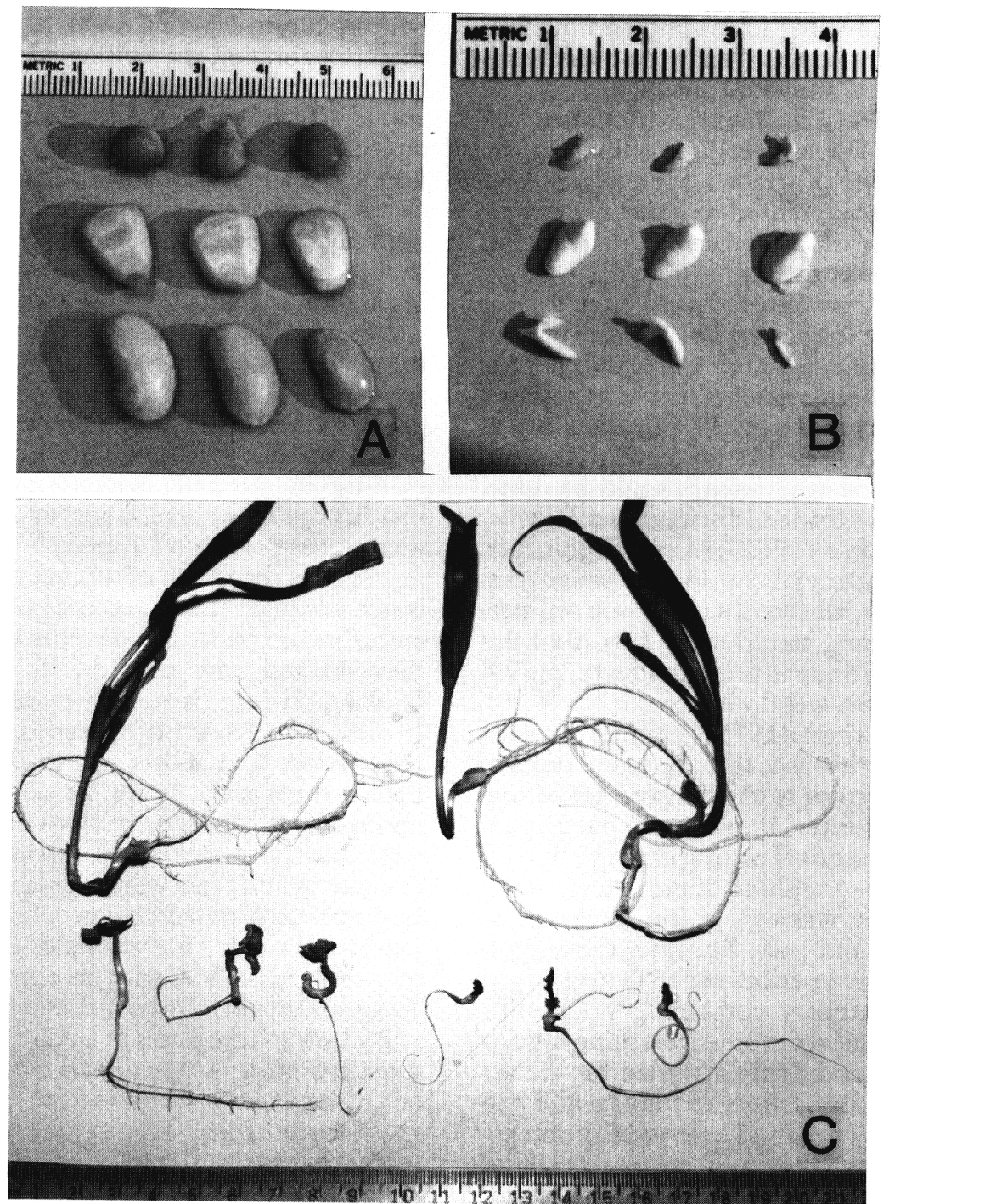

Fig. 1. (A) Opule size before embryo excision. (B) Embryo size after excision. (C) Embryo growth on MS media 3 weeks after removal; corn on the top; bean, three plants at lower left; and pea, tbree plants on lower right.

able during most of the year, so obtaining relatively inexpensive plant material should not be a problem. They also represent warm- and coolseason crops, which would be of interest if temperature were to be a treatment in further investigations.

Of the three, corn was easiest to excise and pea was most difficult. Corn was easy because it was possible to identify on which side of the seed the embryowas positioned before seedcoat removal, and its seed shape made it easier to handle. Pea was difficult primarily because its roundness made it difficult to stabilize while removing the seedcoat.

A workshop for high school vocational agriculture teachers provided an opportunity to observe how someone with little to no experience could perform the laboratory exercise. All gen- erally did well-no cultures were contaminated and, as expected, they found corn to be easiest and pea the most difficult. At first, they also had difficulty identifying embryos. It would be helpful to have excess seed for practice before actually removing embryos for culturing.

The laboratory exercise described here is only a beginning. It provides the basis for exposing students to embryo rescue techniques and shows some of the benefits of embryo rescue. It also allows for investigation of factors influencing embryo germination and growth (media components and concentrations, light quantity and quality, temperature, and embryo age) and how different species react to similar conditions.

\section{Literature Cited}

Emershad, R.L., D.W. Ramming, and M.D. Serpe. 1989. In ovulo embryo development and plant formation from stenospermic genotypes of Vitis vinifera. Amer. J. Bot. 76:397-402.

Gamborg, O.L., R.A. Miller, and K. Ojima. 1968. Nutrient requirements of suspension cultures of soybean root cells. Expt. Cell Res. 50:151-158.

Gantotti, B.V. and K.K. Kartha. 1986. Pea, p. 370-418. In: D.A. Evans, W.R Sharp, and P.V. Ammirato (eds.). Handbook of plant ceil culture. vol. 4. Macmillan, New York.

Goldy, R., R. Emershad, D. Ramming, and J. Chaparro. 1988. Embryo culture as a means of introgressing seedlessness from Vitis vinifera to $V$. rotundifolia. HortScience 23:886-889.

Ramming, D. 1983. Embryo culture, p. 136-144. In: J.N. Moore and J. Janick (eds.). Methods in fruit breeding. Purdue Univ. Press, West Lafayette, Ind.

Reinert, J. and M.M. Yeoman. 1982. Plant cell \& tissue culture: Alaboratory manual. Springer-Verlag, New York. p. 56-58.

Smith, C.A., C.H. Bailey, and L.F. Hough. 1969. Methods for germinating sees of some fruit species with special reference to growing seedlings from immature embryos. New Jersey Agr. Expt. Sta. Bul. 823. 